\title{
NOTAS SOBRE EL INCUMPLIMIENTO Y LA RESPONSABILIDAD CONTRACTUAL
}

\author{
Carlos VATTIER FuENZALIDA \\ CATEDRÁtICO DE DERECHO CIVIL \\ UNIVERSIDAD DE BURGOS
}

s $\quad$ u $\quad$ m a $\quad$ r i o

I. Introducción. 2. Derecho español. 3. Derecho inglés. 4. Derivaciones anglosajonas. 5. Modernización del BGB. 6. Obras citadas.

\section{Introducción.}

La unificación del Derecho de obligaciones y contratos despertó un gran interés en los ámbitos universitarios especialmente, durante los felices años noventa, desde la publicación del célebre trabajo del Profesor G. GANDOLFI en I992, que coincidía con la instauración del mercado interior sin fronteras, a partir del año siguiente. La tesis básica era la idea jacobina según la cual, dada la experiencia del siglo XIX, la unidad del mercado exigía un código único, que la burocracia comunitaria ha degradado hoy a una especie de vademécum, el llamado «marco común de referencia», previsto para el año 2007, al que debe seguir el no menos ambiguo «instrumento facultativo», esto es, el futuro código al que las partes podrán adherirse voluntariamente, que viene a quedar postergado de hecho casi sine die.

Con todo, fruto de esta idea son los dos importantes textos conocidos como Principios de la Comisión Lando y como Anteproyecto de Pavía, que no sólo pretenden regular todas las vicisitudes de la relación obligatoria sino también el incumplimiento de la obligación y la responsabilidad contractual; en lo que aquí nos interesa, ambos textos concuerdan en la noción unitaria de incumplimiento, con algún acento distinto, como advierte A. VAQUER ALOY, pero no son exactamente iguales en lo que concierne al régimen

\footnotetext{
* Trabajo destinado al libro en homenaje al Profesor Mariano Alonso Pérez.
} 
de las consecuencias patrimoniales que se derivan del mismo. Lo que es extremadamente significativo, pues estos textos, aunque persiguen la unificación, responden a tradiciones jurídicas distintas; recordemos que, mientras el primero es de corte anglosajón, el segundo es marcadamente continental.

En concreto, es bien sabido que sobre las consecuencias patrimoniales del incumplimiento han coexistido tres modelos en Europa, que no se han deformado en los dos últimos siglos, a pesar del constante estudio comparado de sus semejanzas y diferencias. Estos modelos, a falta de mejor denominación, son el modelo latino, el anglosajón y el pandectista, bien representados, respectivamente, por el Código civil español, el Derecho inglés, en especial el aclarado y ordenado por el Contract Code de MCGREGOR, y el BGB. Sin embargo, asistimos en la actualidad a un doble fenómeno que desdibuja este nítido panorama, tanto por la influencia del Derecho anglosajón como por la sobrevenida convergencia del Código español y el Código alemán.

En efecto, por una parte, nos referimos a la notable influencia ejercida por el common law en esta materia. Influencia que se aprecia no sólo en la Convención de Viena sobre la compraventa internacional de mercaderías, aprobada en I980 y vigente en España desde I99I, sino también en la Directiva I999/44, incorporada a nuestro ordenamiento por la Ley $23 / 2003$, de Io de julio, sobre garantías en la venta de bienes de consumo. Como veremos, estas disposiciones concuerdan, no son sólo en su filiación anglosajona, sino en que contemplan soluciones parcialmente coincidentes entre sí. Puesto que la primera se refiere a las relaciones entre empresarios y la segunda a la compraventa celebrada por consumidores, ambas abarcan gran parte de los intercambios transfronterizos. Esta coincidencia, a nuestro juicio, explica en buena medida que la unificación del Derecho contractual europeo no sea una tarea urgente, a lo que contribuirá dentro de poco, con toda seguridad, la responsabilidad civil en la prestación de servicios, a la vista de los nuevos estudios realizados por la Comisión en 2004, tras diez años de inactividad al respecto. En este sentido, tiene razón S. CÁMARA LAPUENTE cuando enlaza el futuro del Derecho de consumo con la posible trayectoria del nuevo instrumento común de obligaciones y contratos.

Por otra parte, el segundo fenómeno a que hacemos referencia es la llamativa convergencia que se da hoy entre determinada interpretación del Código español y el nuevo régimen del incumplimiento que se ha introducido en el Código alemán por la Ley de modernización del Derecho de obligaciones, que ha entrado en vigor en 2002. Aunque los textos legales no sean de la claridad que sería de desear, esta nueva convergencia consiste en la disociación del cumplimiento por equivalente y la indemnización de los daños y perjuicios causados por el incumplimiento. Mientras tal disociación predomina en nuestra doctrina última, parece que se ha consagrado de forma expresa por la mencionada reforma alemana. Pero esta afortunada convergencia, no debe hacernos olvidar que la disociación se contrapone al criterio integrador que mantiene entre nosotros un autorizado sector de la doctrina y predomina en el Derecho anglosajón.

Por eso, para estudiar el panorama actual de la responsabilidad contractual en el contexto europeo, vamos a aludir sucintamente a las tendencias objetivadoras que han imperado en nuestro Derecho; a continuación, veremos un esquema sumario del Derecho inglés, al tiempo que constataremos su palmaria influencia tanto en la Convención como en la Directiva citadas. Tras enunciar las distintas posibilidades de incorporar esta Directiva, intentaremos poner de relieve algunas incoherencias de la Ley 23/2003; examinaremos, en fin, las principales novedades de la reforma del BGB en la materia que nos ocupa, con especial referencia a los supuestos de indemnización por la violación de un deber obligatorio y al resarcimiento en sustitución de la prestación incumplida o imposible. 


\section{Derecho español.}

Poco podemos decir de nuestro Código que no sea suficientemente conocido. De tradición romanista, en materia de responsabilidad contractual recoge las doctrinas del humanismo, tal como fueron tamizadas por R. Pothier. El resultado es una redacción confusa, un régimen insatisfactorio, una lectura en clave subjetivista, que se ha centrado por años en la culpa o la negligencia del deudor, en notable paralelismo con la responsabilidad extracontractual. Hay aquí, asimismo, importantes tendencias hacia la objetivación de la imputación del incumplimiento, igual que en esta última.

Una primera tendencia fue la inversión de la carga de la prueba o, más exactamente, la presunción del culpa del deudor, que la jurisprudencia admite desde los años treinta. Pero se trata tan sólo de una presunción judicial, que depende de las circunstancias del caso y la prueba producida por las partes en el proceso. Otra línea objetivadora fue la distinción de las obligaciones de medios y las obligaciones de resultado, de manera tal que sólo en las primeras el incumplimiento es imputable a la falta de diligencia del deudor, mientras que en las últimas se presenta, en cambio, por la falta del resultado prometido. No obstante, esta distinción, como demostró F. JORDANO FRAGA temprana y lamentablemente perdido para nuestra disciplina- sirve para verificar el hecho del incumplimiento, sin alterar las reglas de la responsabilidad, aparte de que depende de la distribución de los riesgos efectuada por los contratantes. Por eso, es reconducible, en nuestra opinión, a un problema de interpretación de los contratos.

Aunque hay otras manifestaciones objetivadoras, el último episodio está representado por la disociación del cumplimiento por equivalente y el resarcimiento de los daños. Ante esta distinción, nuestra doctrina se muestra dividida. La postura clásica, renovada últimamente por autores tan autorizados como L. DíEZ-PICAZO, J. DELGADO ECHEVERRÍA, C. ROGEL VIDE o F. PANTALEÓN PRIETO, mantiene un realismo integrador, de acuerdo con el cual el equivalente pecuniario de la prestación incumplida se entiende como una partida que forma parte de la indemnización de los daños y perjuicios causados por el incumplimiento; no sólo no se distingue de esta última, sino que el equivalente económico del incumplimiento está sometido a las mismas reglas que la responsabilidad contractual. Una vez acreditada la existencia del daño, esta orientación responde a la práctica de los tribunales que suelen fijar -lo que acaso sea criticable- una indemnización en globo con la finalidad de reintegrar en el patrimonio del acreedor todas las consecuencias derivadas del incumplimiento.

Frente a este realismo integrador, en la literatura más reciente se ha impuesto la tesis del historicismo disociador, que atiende principalmente a los antecedentes históricos y pretende una clara separación de las dos categorías indicadas. En efecto, esta interpretación parte de la distinción entre la aestimatio rei y el id quod interest que, aun cuando se remonta al procedimiento formulario, en el que el demandante debía señalar el importe de la cantidad que reclamaba, nunca fue muy clara en las fuentes clásicas y aparece confundida en las postclásicas, como consecuencia de la sustitución de dicho procedimiento por el extraordinario en el siglo IV. Y sigue la atormentada trayectoria de esta distinción en el Derecho común, pasando por el Proyecto de García Goyena, hasta llegar al régimen actual. Iniciada por la obra sólida y monumental de F. BADOSA COLL, se puede afirmar que esta nueva lectura ha concitado el consenso de los civilistas de la última generación; así, A. CARRASCO PERERA la acoge en su importante comentario al Código civil, M. YZQUIERdo TOLSADA la defiende en su estudio unitario y sistemático sobre la responsabilidad civil, al tiempo que E. LlAMAS POMBo le ha dedicado una extensa y densa monografía, bajo la guía de M. Alonso Pérez. En fin, admitida por F. RiVERO HeRnÁndeZ en la última edición de los Elementos de Lacruz, con lo que cambia la orientación anterior de esta obra, P. DE PABLO 
CONTRERAS, en las lúcidas páginas en que trata el tema, no sólo la comparte, sino le encuentra apoyos solventes en la nueva Ley de Enjuiciamiento Civil de 200 .

Naturalmente que no es éste el momento oportuno para profundizar en tan compleja cuestión, cuyos preceptos clave son los artículos I096, II82 y IIOI del Código civil. De acuerdo con el primero, si el deudor incumple una obligación de dar, el acreedor puede compelerle a cumplir, «independientemente del derecho que le otorga el artículo IIoI»; conforme con el segundo, la obligación se extingue si deviene imposible sin mora ni culpa del deudor, culpa que alude aquí al hecho causante de la imposibilidad; y a la vista del último, cabe la indemnización por el incumplimiento, la mora y cualquier otra contravención de la relación obligatoria. A pesar de la redacción confusa y desordenada de estos preceptos, se entiende ahora que la obligación incumplida se perpetúa y transforma en el equivalente pecuniario -la aestimatio- a la vez que se distingue netamente del resarcimiento de los daños causados por el incumplimiento -el id quod interest-.

De acuerdo con esta concepción, estamos ante pretensiones diferentes, que se rigen por reglas distintas. El cumplimiento por equivalente es el objeto de la acción de cumplimiento, en cuya virtud el acreedor pide la ejecución forzosa de la prestación incumplida, y es un subrogado, por tanto, de la ejecución in natura; se trata de una pretensión objetiva, pues procede una vez que el acreedor ha probado que la obligación es exigible y el hecho del incumplimiento, sin que se requiera la culpa del deudor. En cambio, se aplican a la indemnización las reglas propias de la responsabilidad civil. No sólo se exige la prueba del daño que padece el acreedor como consecuencia de la lesión de su derecho de crédito, sino, además, se debe acreditar que el daño es imputable al deudor, normalmente por culpa o negligencia, y el nexo de causalidad jurídica entre el incumplimiento y el daño. En este sentido, la indemnización es una deuda de valor, que se añade eventualmente al equivalente pecuniario y desaparece si el acreedor satisface su interés por otros medios, como puede ser el pago hecho por un tercero, a la vez que exige una prueba independiente y, en su caso, una tasación judicial separada de la pretensión anterior.

Estos detalles parecen ser bastantes para hacerse una idea aproximada de las dos posturas de nuestra doctrina. Sin embargo, a nuestro modo de ver, hay que resaltar que la tesis que acabamos de exponer no está exenta de aspectos problemáticos. Entre otras dificultades, mencionemos las siguientes: I) la perpetuatio obligationis tropieza con el escollo casi insalvable de la novación objetiva; 2) la preferencia por el equivalente pecuniario limita el ius variandi del acreedor en la solidaridad pasiva; 3) las garantías de la obligación incumplida deberían extinguirse y no extenderse, salvo pacto expreso, al resarcimiento de los daños; 5) la prescripción del cumplimiento por equivalente comienza desde que la obligación es exigible, mientras que el dies a quo de la indemnización es el del incumplimiento o, en rigor, el día en que se producen los daños que el acreedor invoca; 6) el supuesto extremo del incumplimiento sin daños adicionales es una hipótesis de laboratorio que no suele presentarse en la realidad, salvo debido a su falta de alegación y prueba por el acreedor, puesto que siempre padece, como mínimo, el daño moral consistente en tener que reclamar la indemnización. Aunque estas dificultades sean solventables, como lo ha intentado E. Llamas, no se puede negar que existen, que la disociación suscita problemas y que la doble prueba y la doble tasación es un artificio de escasa utilidad práctica. Con todo, debemos insistir en que esta postura predomina en la doctrina de los últimos años. 


\section{Derecho inglés.}

El Derecho anglosajón que rige el incumplimiento de los contratos es conocido, simple, objetivo, casi automático, ya que se basa en la strict liability del deudor. A estas características se debe su extraordinaria influencia extraterritorial. Para su estudio podemos orientarnos por el Contract Code que, si no prosperó en su día, fue por consideraciones de oportunidad política, pero no por ser infiel al ordenamiento inglés en vigor, salvo las importantes novedades que su propio autor se encarga de destacar y no inciden en la materia que nos ocupa.

Existe aquí una noción unitaria de incumplimiento que abraza todos los supuestos posibles de falta de satisfacción del acreedor. Como dice el texto citado, incurre en incumplimiento aquella parte del contrato que deja de cumplir por completo cualquier obligación que le incumbe, o la cumple tarde o sólo en parte, o que de cualquier otro modo no se ajuste a sus obligaciones, impuestas por el contrato $u$ otras fuentes obligatorias de índole diferente (art. 30I). Un supuesto especial es el incumplimiento sustancial que se presenta, junto a la falta total de la prestación, cuando no sea razonable exigir al acreedor el cumplimiento de la suya; y por eso, cabe en este caso la resolución, con efectos ex nunc (arts. 306 y 307). Pero el incumplimiento se extiende también a la falta de prestación no esencial, al cumplimiento defectuoso, al tardío y hasta al incumplimiento anticipado, esto es, aquél en que sea evidente que, según las circunstancias del caso, el deudor no va a cumplir la prestación debida (art. 303), en términos que recuerdan los del artículo iı29 del Código civil..

Los remedios, que son derechos sustantivos y no sólo acciones procesales, dependen del tipo de incumplimiento de que se trate. Salvo que sea sustancial, las partes siguen vinculadas, y el acreedor puede exigir el cumplimiento específico y reclamar los daños y perjuicios causados por el incumplimiento (art. 309); nótese que, mientras el primero es excepcional, la última constituye, en cambio, la regla general. De aquí que, al lado de la indemnización, procedan según los casos la subsanación del defecto, la sustitución del objeto, la rebaja del precio o la restitución de los provechos obtenidos. Aunque el resarcimiento exige la prueba del daño (art. 432), la indemnización abarca todos los daños y perjuicios probados por el acreedor, sin disociar el equivalente pecuniario de la prestación incumplida y la indemnización de los demás daños que padezca, puesto que se valoran, como criterio principal, con arreglo a la pérdida sufrida, esto es, con la finalidad de situar al demandante en la situación que hubiese alcanzado con el cumplimiento del contrato por ambas partes (art. 434); por eso, a tenor del Contract Code, «el resarcimiento se concede generalmente como una suma global de dinero expresada en libras esterlinas» (art. 43I).

Una excepción a esta responsabilidad es la frustración del fin del contrato, que se da por el cambio brusco de las circunstancias, como en los célebres casos de la coronación del rey Eduardo VII o los derivados de la segunda guerra mundial; pero no tiene lugar por los debidos al hecho propio del deudor, ni a causa del cambio provocado por él, o por los casos fortuitos que ha asumido expresa o tácitamente. En suma, el contrato se frustra, por regla general, en los casos de vis maior. Ello se debe, como decíamos, a la responsabilidad estricta que incumbe a cada contratante y que fue consagrada ya en el caso Paradine vs. Jane de I647; aunque se ha mantenido hasta el presente, se ha mitigado en numerosas ocasiones, por ejemplo, por el incendio de una sala de conciertos objeto del contrato (Taylor vs. Caldwell, I863).

En fin, el fundamento de este régimen reside en que el contrato se concibe, a juicio de los conocidos comparatistas K. ZWEIGERT y H. KÖTZ, como un cruce de promesas que obliga a alcanzar el resultado, de manera que a cada parte incumbe la garantía del 
cumplimiento de sus respectivas prestaciones; aparte de la frustración, caben también las cláusulas de exclusión de responsabilidad, que suelen ser expresas, cuando no están prohibidas por la protección de los consumidores. De este modo, el deudor sólo se libera de la obligación, o bien por frustración del contrato, o bien por exclusión de la responsabilidad, con total independencia de su conducta, o del mayor o menor esfuerzo que haya desplegado en la fase de ejecución del contrato; por eso, para determinar si hubo o no incumplimiento, no se mira tanto a la diligencia o negligencia de los contratantes, sino fundamentalmente a los riesgos asumidos o a las garantías otorgadas por el deudor. Y de aquí que esto dependa en una medida importante, de nuevo, de la interpretación del contrato y la integración de su contenido por los llamados términos implícitos, que se basan principalmente en los usos y la buena fe.

\section{Derivaciones anglosajonas.}

La exactitud casi matemática del modelo anglosajón le confiere un indudable atractivo, sobre todo en el tráfico internacional y para los empresarios que se sitúan en el mercado por el lado de la oferta; por eso, no debe extrañarnos que rija no sólo en el tercio del mundo en que se aplica el common law, sino que su influencia se extienda a países de tradición jurídica diferente. Es el caso de los Estados miembros de la Unión Europea, como España, que no sólo son Estados partes de la Convención de Viena, sino que han debido incorporar la Directiva I999/44. Y un somero repaso de estas disposiciones permite comprobar fácilmente el decidido influjo que ha ejercido el régimen anglosajón del incumplimiento contractual en cada una de ellas. Influjo que se irradia, además, a las propuestas doctrinales encaminadas a la unificación del Derecho europeo de contratos, el cual, si bien es ostensible en los Principios de la Comisión Lando, está un tanto más difuminado en el Anteproyecto de Pavía, pues éste parece acoger la disociación del equivalente económico y el resarcimiento de los daños causados por el incumplimiento, como más adelante veremos.

En efecto, según hemos adelantado, la Convención de Viena se inspira en el Derecho anglosajón, lo que es muy significativo ya que representa un punto de equilibrio y de consenso a escala mundial, logrado tras una trabajosa gestación de cerca de medio siglo de duración. Es sabido que la Convención impone al vendedor la obligación de conformidad, que también se llama de garantía, en cuya virtud debe entregar al comprador mercaderías que sean conformes con lo estipulado en el contrato; esta conformidad se refiere a la cantidad, calidad, tipo y envases o embalajes, y por eso se prevé una lista cerrada de supuestos de falta de conformidad. Los supuestos consisten en la falta de aptitud de las mercaderías para el uso ordinario o para el uso especial acordado por las partes, en los desajustes de las mismas con la muestra o el modelo enseñado al comprador o, en fin, en que los envases sean inhabituales o inadecuados (art. 35).

De acuerdo con el modelo anglosajón, la falta de conformidad es un supuesto de incumplimiento del contrato, al que son de aplicación los remedios generales de la responsabilidad contractual. De aquí que proceda, ante todo, el cumplimiento específico in natura, que se considera excepcional ya que sólo tiene lugar si rige en el Estado parte para los contratos no amparados por la Convención (art. 28). A continuación, caben a elección del comprador otras medidas que son comparables al anterior, sólo que no consisten en la ejecución forzosa de la prestación incumplida; se trata de la sustitución de las mercaderías defectuosas, la subsanación de la disconformidad siempre que sea razonable e incluso después de la fecha de entrega, la fijación de un plazo razonable para que el vendedor 
cumpla sus obligaciones o la rebaja proporcional del precio, a las que se une la resolución del contrato si la falta de conformidad es esencial (arts. 45 y ss).

En todo caso, por último, el comprador puede reclamar además la indemnización de los daños y perjuicios, que es compatible con las medidas anteriores y comprende, por regla general, la pérdida sufrida por el comprador y la ganancia dejada de obtener como consecuencia del incumplimiento, con el límite de la pérdida prevista o previsible al momento de celebración del contrato; en particular, en caso de resolución, se incluye también la diferencia de precio del contrato incumplido y el contrato de reemplazo (arts. 74 y 75). En esta indemnización, por consiguiente, no tiene cabida el equivalente pecuniario de la prestación incumplida, pues, aunque está comprendido obviamente en la pérdida que padece el acreedor, es claro que ésta abarca además los otros gastos y daños derivados del incumplimiento que integran el daño emergente; piénsese, por ejemplo, en gastos tales como los causados por las reclamaciones hechas por el acreedor al deudor o a terceros, los transportes, las gestiones bancarias, la renegociación del contrato de reemplazo $u$ otros similares, y en daños como los causados por la infracción de los deberes de protección que incumben al deudor o el daño moral que sufre el acreedor por el incumplimiento. Lo que se ha de entender así, a nuestro juicio, puesto que ninguno de estos gastos o daños entran en el lucrum cessans.

Por su parte, la Directiva I999/44 sigue de cerca el sistema previsto por la Convención, con la notable salvedad de la indemnización de los daños y perjuicios. Recordemos que su ámbito de aplicación es reducido. Por un lado, se limita a los contratos de compraventa y suministro, a veces en conexión con contratos de transporte y de obra de fabricación o de instalación, siempre que se celebren exclusivamente entre profesionales y consumidores; y por otro lado, su objeto se contrae a bienes corporales muebles (art. I). Según señala J. LETE ACHIRICA, el software, por ejemplo, puede considerarse como un mueble corporal ya que, al ser utilizado, ocupa un espacio en la memoria del ordenador. Tan próxima está la Directiva a la Convención que establece, igual que ésta, la obligación de conformidad a cargo del vendedor, y reproduce los supuestos de falta de conformidad, a los que añade, en sustitución de los envases, los errores en la instalación bajo las instrucciones del vendedor y los desajustes del bien con lo anunciado en la publicidad o en el etiquetado, a no ser que el vendedor pruebe que desconocía el anuncio, que lo corrigió al momento de contratar o que no pudo influir en la voluntad del consumidor (art. 2). Asimismo, la Directiva contempla unos remedios semejantes a los que acabamos de exponer, sólo que son de aplicación escalona, además de la llamativa exclusión del resarcimiento de los daños causados por la disconformidad.

Pese a su ámbito limitado, este régimen tiene importantes repercusiones, que inciden en el Derecho común, tanto en el Código civil como en el Código de comercio. Ante todo, es evidente que suprime la responsabilidad especial por vicios ocultos y las acciones edilicias para los contratos de compraventa comprendidos en la Directiva; por otra parte, trastoca el concepto de incumplimiento de las obligaciones y lo amplía a todos los supuestos de falta de conformidad, si bien es cierto que éstos eran ya asimilables al cumplimiento defectuoso, conforme a la jurisprudencia sobre el aliud pro alio; en fin, no menos trascendente es que acoge los remedios anglosajones, salvo la indemnización, los cuales, aunque no difieren demasiado de la resolución del contrato y la rebaja del precio, ahora están jerarquizados y restringen las opciones que corresponden consumidor, aparte de ser más numerosos que los previstos por el Derecho común.

Es debido a estas repercusiones que han surgido distintas vías a la hora de incorporar el texto comunitario a los distintos ordenamientos internos, que son las llamadas pequeña solución y gran solución. Sin entrar en los pormenores, mientras la primera se ciñe estrictamente al ámbito de aplicación y traspone dicho texto sólo para el Derecho del consumo, sea en un código o en una ley especial, la última, en cambio, atiende a estas u 
otras repercusiones y encuadra el nuevo régimen en el campo del Derecho común, al que se añaden normas particulares para la protección de los consumidores. Incluso cabe una solución intermedia que consiste en incorporar la Directiva al Código civil, junto con reformar y actualizar la disciplina del contrato de compraventa. Esta solución intermedia se ha defendido entre nosotros, tanto por A. CARRASCO PERERA, con otros colaboradores, como por A. M. Morales Moreno, y la ha hecho suya la Comisión General de Codificación que, según parece, ha presentado un anteproyecto de texto articulado al Ministerio de Justicia.

No obstante, se ha impuesto entre nosotros la solución simple de la ley especial, la Ley 23/2003, que lleva a cabo una transcripción casi literal de la norma comunitaria. No hace falta que nos detengamos en ella, pero conviene llamar la atención sobre algunas de sus incoherencias. Una primera es que, en contra de las inclinaciones que prevalecen en la doctrina, dispone la promulgación de un verdadero código de consumo, esto es, un texto refundido que regularice, aclare y armonice las normas nacionales y comunitarias en materia de consumo, dentro del plazo de tres años, del que ha transcurrido al día de hoy más de la mitad (Disp.fin. $4^{\mathrm{a}}$ ).

Y otra incoherencia reseñable de la Ley es que consagra su incompatibilidad el saneamiento de los vicios ocultos y proclama al mismo tiempo que «en todo caso, el comprador tendrá derecho, de acuerdo con la legislación civil y mercantil, a ser indemnizado por los daños y perjuicios derivados de la falta de conformidad» (Disp.ad.). Lo que es grave, en nuestra opinión, por varias razones. Por un lado, deforma el régimen de la Directiva y constituye un obstáculo a la armonización perseguida por la Unión Europea; por otro lado, presupone la mala fe del vendedor, a la par que asimila el régimen del saneamiento al del incumplimiento y los vicios ocultos a la falta de conformidad; por último, confiere una protección de mayor intensidad al comprador común, acaso empresario o profesional, que al consumidor, por lo que contradice la ratio de la propia Ley.

Finalmente, el Derecho anglosajón ha influido también, en una medida variable, en las propuestas que propician la unificación del Derecho de obligaciones y contratos en la Unión Europea. Esta influencia se constata de un modo manifiesto en los Principios de la Comisión Lando, cuyo régimen está muy próximo, por lo demás, al del Contract Code. En efecto, los Principios consagran, aunque no definen, una noción amplia de incumplimiento, del que se responde siempre, a no ser que se deba a un impedimento incontrolado e imprevisto (art. 8.IoI). Los remedios de que dispone el acreedor son los mismos que ya conocemos: la ejecución específica, la suspensión del propio cumplimiento, la resolución, la rebaja del precio y la indemnización de los daños y perjuicios; todos los cuales son compatibles y acumulables entre sí (art. 8.IO2). En particular, la indemnización tiene por objeto reintegrar al acreedor la pérdida sufrida por el incumplimiento, pérdida que comprende, no sólo el daño patrimonial, sino la pérdida no pecuniaria, así como la «pérdida futura que razonablemente se prevea que puede ocurrir» (art. 9.504). Como decíamos a propósito de nuestro Código, es indudable que el equivalente económico de la prestación incumplida está comprendido aquí en dicha pérdida, pero es igualmente claro que no la agota ni se identifica con ella.

Asimismo, para el Anteproyecto de Pavía hay incumplimiento cuando las partes adoptan un comportamiento diferente al previsto en el contrato (art. 89), el cual se produce, entre otros supuestos, por la violación eficaz y el incumplimiento de los deberes de protección; la primera se presenta en la hipótesis en que, por pacto expreso de los contratantes, el deudor puede apartarse del contrato por recibir una oferta de un tercero que sea más ventajosa que la prestación debida (art. 98), mientras el último ocurre cuando el deudor daña al acreedor, a sus auxiliares o a sus bienes durante o a causa del cumplimiento del contrato y siempre que constituya una consecuencia inmediata y directa de la misma (art. 99). Junto a la suspensión de la prestación, el incumplimiento anticipado, el plazo de 
gracia, la ejecución específica, la reducción del precio y la resolución, el acreedor tiene derecho de la indemnización de los daños y perjuicios. Esta indemnización procede en cualquier caso de incumplimiento, de incumplimiento inexacto o de retraso, salvo que intervenga una causa extraña que sea a la vez imprevisible e irresistible; aunque es independiente de la culpa, el empresario o profesional que actúe con diligencia en los campos del saber en que no hay conocimientos científicos consolidados, sólo responde por culpa grave (art. I62); indemnización que se extiende, no sólo a la pérdida sufrida y a la ganancia dejada de obtener, sino también al daño moral causado al acreedor y al daño patrimonial reflejo que padecen los acreedores de este último en caso de muerte o lesiones graves (art. I63). Estos remedios son acumulabes, en fin, a no ser que sobrepasen del perjuicio sufrido por el acreedor o provoquen una situación insostenible para el deudor (art. I7I).

A pesar de los rasgos originales que hemos resaltado, salta a la vista que el Anteproyecto mantiene cierto paralelismo con las soluciones del Derecho anglosajón. No obstante, M. YZQUIERDO, en su interesante comentario del texto de Pavía, ha puesto de relieve que el Anteproyecto contiene datos suficientes como para entender que distingue, por una parte, algunos remedios conferidos al acreedor ante el incumplimiento y, por otra parte, la indemnización de los otros daños que sufra como consecuencia del mismo. Estos datos se refieren a la pretensión de restitución (art. II5), al plazo suplementario que debe preceder al ejercicio de las pretensiones del acreedor (art. IIo) o la satisfacción de su interés mediante una prestación diferente (art. II2) -en la que que el autor incluye la aestimatio rei, pues se declara de forma expresa que todos estos remedios son compatibles con la indemnización de los daños y perjuicios. Si esto es así, quiere decir que el Anteproyecto ha permanecido fiel al historicismo disociador y que se aproxima, en este aspecto, a la reforma del Código civil alemán.

\section{Modernización del BGB.}

En efecto, es bien sabido que el régimen del incumplimiento era una de las partes más desafortunadas del Código alemán, debido al influjo de F. MOMMSEN para el que el deudor, impulsado acaso por kantiano imperativo categórico, únicamente dejaba de hacer frente a sus obligaciones por imposibilidad o por mora. Nada más entrar en vigor, se observó la omisión del cumplimiento defectuoso y luego la jurisprudencia creó figuras nuevas como la responsabilidad precontractual o la ruptura de la base del negocio. A esto se une la legislación especial, como la famosa Ley de condiciones generales de i976, y la que ha venido incorporando las diferentes Directivas comunitarias sobre consumidores. Tras un intento frustrado de los años ochenta, se promulgó la Ley de modernización de 200I, que ha entrado en vigor al año siguiente.

En lo que aquí nos importa, la reforma consagra una cláusula general de incumplimiento, semejante a nuestro artículo iıo del Código civil, que enumera los distintos supuestos de violación, lesión o contravención de un deber obligatorio (par. 280); además, la Directiva I999/44 se desdobla, pues la falta de conformidad se equipara al incumplimiento (par. 28I.I), mientras que los remedios se llevan al contrato de compraventa (pars. 346 y ss); asimismo, la imposibilidad excluye el deber de prestación, pero permite al acreedor reclamar la indemnización o la resolución (par. 275.4), que son ahora compatibles (par. 325); en fin, se mantiene la responsabilidad subjetiva (par. 276).

A la vista del nuevo parágrafo 280 del Código alemán, hay que distinguir cinco supuestos de indemnización de los daños, que veremos muy esquemáticamente. Ante todo, 
el primero de ellos es el más general ya que se trata de la violación de un deber impuesto por la relación obligatoria, a no ser que el deudor no deba responder de tal violación. Por regla general, se responde, no sólo por dolo, sino por la culpa, que es la normalmente exigible en el tráfico, salvo que sea mayor o menor según el contenido de la obligación, o que el deudor haya asumido la garantía del resultado o el riesgo del suministro. Mientras, M. EBERS cree que esta norma consagra una culpa presunta, cuyo resultado práctico es comparable a la strict liability, E. Deutsch sostiene, en cambio, que no altera la carga de la prueba, de manera que el acreedor debe acreditar la culpa del deudor. Por otra parte, el segundo supuesto es el de la mora que exige, en principio, la intimación o la demanda judicial, si bien hay numerosas excepciones y plazos preestablecidos por la ley (par. 286). Por fin, el tercer supuesto es el de la indemnización en sustitución o en lugar de la prestación, que se presenta en estos tres casos, a saber: a) por falta de cumplimiento (par. 28I); b) por violación de un deber de protección (par. 24I.2) y c) por imposibilidad de la prestación (art. 275).

En cuanto al primero de estos casos, la indemnización en lugar de la prestación vencida procede porque el deudor la ha incumplido o no ha cumplido según lo debido falta de conformidad- , previa la concesión de un plazo razonable para el cumplimiento o la corrección, salvo que concurran circunstancias especiales. Lo que interesa recalcar es que la pretensión de cumplimiento queda excluida en este caso si el acreedor reclama la indemnización, lo que da a entender claramente que estamos ante el equivalente económico de la prestación incumplida.

Por lo que atañe al segundo caso, se trata de la infracción de los deberes accesorios o complementarios de información, protección o seguridad que impone la relación obligatoria. Por virtud de la misma, el acreedor, no sólo puede reclamar al deudor el cumplimiento de la prestación debida, sino que está obligado -y esto es lo añadido por la reforma- a respetar los derechos, bienes jurídicos e intereses de la otra parte. En este caso, cabe la indemnización en lugar de la prestación si ya no se le puede exigir al acreedor que acepte la prestación del deudor y, si el contrato es bilateral, se admite además la resolución (par. 324). Adviértase que en esta hipótesis el daño aparece por la infracción de los mencionados deberes, de modo que, por definición, no está previsto en el contrato, si bien la indemnización se rige por las reglas generales de la responsabilidad contractual.

Por último, la imposibilidad de la prestación excluye la pretensión del acreedor al cumplimiento, de forma automática, a juicio de J. ALBIEZ DOHRMANN, aun cuando puede exigir la indemnización en lugar de la prestación imposible o, en su caso, la resolución del contrato, siempre que sea imputable a culpa o dolo del deudor. Se debe resaltar que la imposibilidad se concibe en términos amplios; así, abarca tanto la imposibilidad legal como la material, la subjetiva lo mismo que la objetiva, la llamada imposibilidad práctica, o sea la que exige al deudor un esfuerzo desequilibrado frente al interés del acreedor, y la imposibilidad ética, es decir, la prestación personalísima del deudor que resulta inexigible, pero no se extiende a la alteración subjetiva u objetiva de la base del negocio (par. 313). Sin embargo, es irrelevante que la imposibilidad sea sobrevenida $u$ originaria, pues ésta no afecta a la eficacia del contrato, pudiendo el acreedor reclamar, a su elección, la indemnización en lugar de la prestación o el reembolso de los gastos (par. 3IIa).

Es de notar que esta última alternativa se presenta siempre que el acreedor ostenta el derecho a pedir la indemnización en sustitución de la prestación, pues puede solicitar, en su lugar, el resarcimiento de los gastos que han devenido infructuosos por el incumplimiento, la violación de deberes obligatorios o la imposibilidad, siempre que los hubiere hecho en la confianza de recibir la prestación y sea justo pedir su restitución, salvo que la finalidad de estos gastos tampoco se hubiera alcanzado, sin la lesión del deber por parte del deudor (par. 284). Ello dependerá probablemente de las circunstancias del caso y de la conveniencia probatoria del acreedor, sin que se deba deducir de aquí que la 
indemnización en lugar de la prestación se limite estrictamente al interés negativo, puesto que el acreedor puede optar tanto por dicha indemnización como por el reembolso de los gastos útiles. Con todo, es de notar que, como recuerda J. AlbiEZ, con cita de Schultz, esta indemnización es siempre compatible con la reparación de otros daños y perjuicios invocados por el acreedor.

En suma -y con esto terminamos- resulta fácil comprobar la convergencia y la divergencia que anunciábamos al principio. En efecto, es claro que el Código alemán reformado concuerda con nuestra doctrina más reciente, puesto que en uno y otra se propicia la disociación del equivalente económico y el resarcimiento de los daños; próximo a este modelo se sitúa además el Anteproyecto de Pavía. En cambio, la integración de ambos conceptos en una indemnización única impera en el Derecho anglosajón, en las normas supranacionales y en los Principios de la Comisión Lando, postura que comparte un sector importante de la doctrina española. Por eso, ante esta palpable disparidad, es de esperar que el futuro código europeo no sólo la tenga en cuenta sino que acierte a la hora de resolverla.

\section{Obras citadas.}

Albiez Dohrmann, K. J., Un nuevo Derecho de obligaciones. La reforma 2002 del BGB, ADC, 2002.

AlONSO PÉREZ, M., El riesgo en el contrato de compraventa, Madrid, I972.

BADOSA Coll, F., La diligencia y la culpa del deudor en la obligación civil, Barcelona, I987.

CÁmara Lapuente, S., El futuro del Derecho de consumo en el nuevo entorno del Derecho contractual europeo, en Derecho Privado de Consumo, coordinadora $\mathrm{M}^{\mathrm{a}}$. J. Reyes López, Valencia, 2005.

Carrasco Perera, A., en Comentarios al Código Civil y Compilaciones Forales, XV-I, Madrid, I989.

Carrasco Perera, A., Cordero lobato, E. Y Martínez Espín, P., Transposición de la directiva comunitaria sobre venta y garantías de los bienes de consumo, en EC, 52, 2000.

Delgado EcheVerría, J., en Elementos de Derecho Civil, II-I, Barcelona, I985.

DEUTSCH, E., Die Fahrlässigket im neuen Schuldrecht, en AcP, 6, 2002.

DíeZ-Picazo Y Ponce De León, L., Fundamentos del Derecho Civil Patrimonial, II, Madrid, I993.

Díez-Picazo, L., Roca Trias, E. Y A. M. Morales Moreno, Los Principios del Derecho Europeo de Contratos, Madrid, 2002.

EBERS, M., La nueva regulación del incumplimiento contractual en el BGB, tras la Ley de modernización del Derecho de obligaciones de 2002, en ADC, 2003.

GANDOlfi, G., Pour un Code européen des contrats, en RTDC, I992.

JORDANO FRAGA, F., Obligaciones de medios $y$ de resultados. (A propósito de alguna jurisprudencia reciente), en ADC, I99I. 
Llamas Pombo, E., Cumplimiento por equivalente y resarcimiento del daño al acreedor (entre la «aestimatio rei» y el «id quod interest»), Madrid, I999.

LETE ACHIRICA, J., La transposición de la Directiva 1999/44 en el Derecho español mediante la Ley de 10 de julio de 2003 de garantías en la venta de bienes de consumo, en Garantías en la venta de bienes de consumo. Les garanties dans la vente de biens de consommation, a cargo del mismo, Santiago de Compostela, 2004.

MCgRegor, H., Contract Code. Proyecto redactado por encargo de la Law Commission inglesa, traducción y nota preliminar por J. M ${ }^{a}$ de la Cuesta Sáenz y C. Vattier Fuenzalida, Barcelona, I996.

MommSEn, F., Die Unmöglichket der Leistung, I853.

Morales Moreno, A. M., Adaptación del Código civil al Derecho Europeo: La compraventa, en ADC, 2003 .

Pablo Contreras, P. de, en Curso de Derecho Civil (II), Madrid, 2000.

PANTALEÓn PRIETO, F., El sistema de responsabilidad contractual. Materiales para un debate, en ADC, I99I.

Rivero HernándeZ, F., en Elementos de Derecho Civil, II-I, Madrid, I999.

Rogel VIDE, C., Derecho de obligaciones y contratos, Barcelona, I997.

VAquer Aloy, A., Incumplimiento del contrato y remedios, en Derecho Privado Europeo, coordinador Sergio Cámara Lapuente, Madrid, 2003.

YzQuierdo Tolsada, M., Sistema de responsabilidad civil, contractual y extracontractual, Madrid, 200I.

Yzquierdo Tolsada, M., en Código Europeo de Contratos. Academia de Iusprivatistas Europeos (Pavía). Comentarios en homenaje al Prof. D. José Luis de los Mozos y de los Mozos, dirigidos por C. Vattier, J. M ${ }^{a}$ de la Cuesta y J. M ${ }^{a}$ Caballero, II, Madrid, 2003.

ZWEIGERT, K. Y KöTZ, H., An Introduction to Comparative Law, II, traducido al inglés por T. Weir, Oxford, I987. 